\title{
Germanium Nanoparticle-Dispersed Reduced Graphene Oxide Balls Synthesized by Spray Pyrolysis for Li-Ion Battery Anode
}

\author{
Jin Koo Kim, Gi Dae Park, and Yun Chan Kang ${ }^{\dagger}$ \\ Department of Materials Science and Engineering, Korea University, Seoul 02473, Korea \\ (Received October 18, 2018; Revised December 5, 2018; Accepted December 5, 2018)
}

\begin{abstract}
Simple fabrication of a powdered Ge-reduced graphene oxide (Ge-rGO) composite via spray pyrolysis and reduction is introduced herein. Successful incorporation of the rGO nanosheets with Ge hindered the aggregation of Ge and conferred enhanced structural stability to the composite by alleviating the mechanical stress associated with drastic volume changes during repeated cycling. The Li-ion storage performance of Ge-rGO was compared with that of powdered Ge metal. The reversible discharge capacity of $\mathrm{Ge}-\mathrm{rGO}$ at the $200^{\text {th }}$ cycle was $748 \mathrm{~mA} \mathrm{~h} \mathrm{~g}^{-1}$ at a current density of $1.0 \mathrm{~A} \mathrm{~g}^{-1}$ and Ge-rGO showed a capacity of 375 $\mathrm{mA} \mathrm{h} \mathrm{g}{ }^{-1}$ even at a high current density of $5.0 \mathrm{~A} \mathrm{~g}^{-1}$. The excellent performance of Ge-rGO is attributed to the structural robustness, enhanced electrical conductivity, and formation of open channels between the rGO nanosheets, which facilitated electrolyte penetration for improved Li-ion diffusion.
\end{abstract}

Key words : Lithium ion batteries, Germanium, Graphene, Carbon composite, Spray pyrolysis

\section{Introduction}

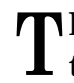
he two key requirements for advanced lithium-ion batteries (LIBs) are higher power and energy densities, which are crucial factors for achieving quick-charge and long lifespan for a single charge, respectively. ${ }^{1-4)}$ From this viewpoint, researches have focused on developing alternative electrode materials with high rate performance and reversible capacities. Ge, a group IV element, has therefore been considered as one of the most promising anode materials for LIBs. ${ }^{4-12)}$ Although its theoretical capacity (1600 mA $\left.\mathrm{h} \mathrm{g}^{-1}\right)$ does not match up to that of $\mathrm{Si}\left(4200 \mathrm{~mA} \mathrm{~h} \mathrm{~g}^{-1}\right)$, Ge has many advantages over $\mathrm{Si}$. Compared with those of $\mathrm{Si}$, the $\mathrm{Li}$ ion diffusivity of Ge is 400 times higher and the electrical conductivity is $10^{4}$ times higher. ${ }^{12-20)}$ However, similar to $\mathrm{Si}$, Ge suffers from drastic volume changes during lithiation and delithiation. This results pulverization of the electrode, which leads to huge capacity fading. ${ }^{18-25)}$ In light of these concerns, various strategies for buffering such huge volume changes have been proposed based on the introduction of rationally designed nanostructures.

For example, Park et al. prepared Ge nanotubes by exploiting the Kirkendall effect. ${ }^{9)}$ Wang et al. synthesized Ge nanoparticles by magnesiothermic reduction. ${ }^{18)} \mathrm{Gu}$ et al. demonstrated the template-free preparation of a Ge nanowire film electrode. ${ }^{26)}$ Incorporation of Ge with carbon is another attractive strategy as carbon confers improved stability to the resulting $\mathrm{Ge}-\mathrm{C}$ composite by hindering aggre-

\footnotetext{
${ }^{\dagger}$ Corresponding author: Yun Chan Kang

E-mail : yckang@korea.ac.kr

Tel : +82-2-3290-3268 Fax : +82-2-928-3584
}

gation of Ge during repeated cycling. ${ }^{27-33)}$ For instance, Gao et al. synthesized a Ge/graphene carbon nanotube hybrid. ${ }^{30)}$ $\mathrm{Xu}$ et al. reported Ge nanoparticles encapsulated in N-doped reduced graphene oxide. ${ }^{31)}$ Both of these species showed stable cycling performance over 200 cycles.

Spray pyrolysis, which is a simple and scalable process that is used for the preparation of various nanocomposites, can also be efficiently applied to the synthesis of $\mathrm{Ge}-\mathrm{C}$ composites. In this study, we prepared Ge nanoparticle-dispersed reduced graphene oxide (rGO) balls by simple reduction of a $\mathrm{GeO}_{2}-\mathrm{rGO}$ balls obtained by spray pyrolysis. rGO serves as a robust buffer for the volume changes during lithiation/delithiation and hinders aggregation of Ge. In addition, hybridization of rGO with Ge leads to greatly improved electrical conductivity. The enhanced Li-ion storage performance of $\mathrm{Ge}-\mathrm{rGO}$ is demonstrated relative that of Ge metal powder.

\section{Experimental Procedure}

\subsection{Sample preparation}

The Ge nanoparticle-dispersed reduced graphene oxide (rGO) (Ge-rGO) balls were prepared by spray pyrolysis and $\mathrm{H}_{2}$ gas reduction. The spray pyrolysis process is thoroughly described in our previous report. ${ }^{24)}$ The spray solution was prepared by dissolving $2.09 \mathrm{~g}$ of $\mathrm{GeO}_{2}(99.999 \%$, Junsei) in distilled water with ammonia $\left(\mathrm{NH}_{4} \mathrm{OH}\right.$, Samchun) under mild heating. Graphene oxide (GO) was obtained by a modified Hummer's method. The as-obtained GO was redispersed $\left(1 \mathrm{mg} \mathrm{mL}^{-1}\right)$ in the above solution and sonicated for 1 h. The total volume of the colloidal solution was $500 \mathrm{~mL}$. The temperature of the furnace was fixed at $500^{\circ} \mathrm{C}$. The 
solution was atomized and carried by $\mathrm{N}_{2}$ gas at a flow rate of $10 \mathrm{~L} \mathrm{~min}{ }^{-1}$. An appropriate amount of as-synthesized powder was transferred to the tubular furnace and heat-treated at $450^{\circ} \mathrm{C}$ for $1 \mathrm{~h}$ with $10 \% \mathrm{H}_{2} / \mathrm{Ar}$ gas to obtain the $\mathrm{Ge}-$ reduced graphene oxide (Ge-rGO) composite powder. For comparison, Ge metal powder was prepared by reducing commercial $\mathrm{GeO}_{2}$ powder at $450^{\circ} \mathrm{C}$ for $3 \mathrm{~h}$.

\subsection{Characterization}

Scanning electron microscope (SEM; TESCAN, VEGA3) and field-emission transmission electron microscope (TEM; JEOL, JEM-2100F) were employed to observe the morphologies of the samples. X-ray diffraction (XRD; X'Pert PRO MPD) measurements were conducted with $\mathrm{Cu}-\mathrm{K}_{\alpha}$ radiation. Thermogravimetric analysis (TGA; SDT Q600) was conducted in air with a ramping rate of $10^{\circ} \mathrm{C} \mathrm{min}^{-1}$ to estimate the amount of carbon in the sample.

\subsection{Electrochemical measurements}

The lithium ion storage properties of the samples were characterized by assembling 2032-type coin cells. The detailed electrode preparation method and cell configuration are thoroughly described in our previous report. ${ }^{34)}$ The cell was cycled over the potential range of $0.001-3 \mathrm{~V}$ at various current densities. Cyclic voltammetry was conducted at a scan rate of $0.1 \mathrm{mV} \mathrm{s}^{-1}$. The electrochemical impedance spectroscopy (EIS) was conducted over the frequency range of $0.01 \mathrm{~Hz}-100 \mathrm{kHz}$ by the potentiostat/galvanostat instrument (ZIVE SP1, WonA Tech).

\section{Results and Discussion}

The SEM images of the $\mathrm{GeO}_{2}-\mathrm{rGO}$ balls prepared by spray pyrolysis are shown in Fig. 1. The balls are crumpled and irregularly shaped. The morphologies of the Ge-rGO balls obtained by heat treatment under reducing atmosphere are shown in Fig. 2. The SEM and TEM images in Figs. 2(a) and (b) confirm that the original morphology of the powder was maintained and no crystal growth of Ge was occurred. A clear distinction between the Ge nanocrystals and rGO sheets was observed in the high-resolution TEM image in Fig. 2(c), and the lattice image in the inset of
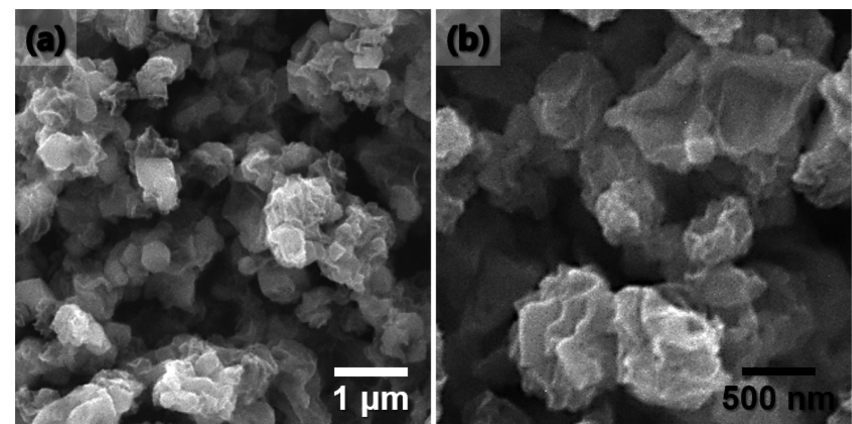

Fig. 1. SEM images of $\mathrm{GeO}_{2}-\mathrm{rGO}$ powder prepared by spray pyrolysis.
Fig. 2(c) reveals fringes separated by $0.33 \mathrm{~nm}$, which correspond to the (111) plane of cubic Ge. The selected-area electron diffraction (SAED) pattern and XRD pattern, respectively presented in Figs. 2(d) and 3(a), also confirmed the successful formation of cubic Ge. The elemental mapping images in Fig. 2(e) demonstrate the homogeneous distribu-
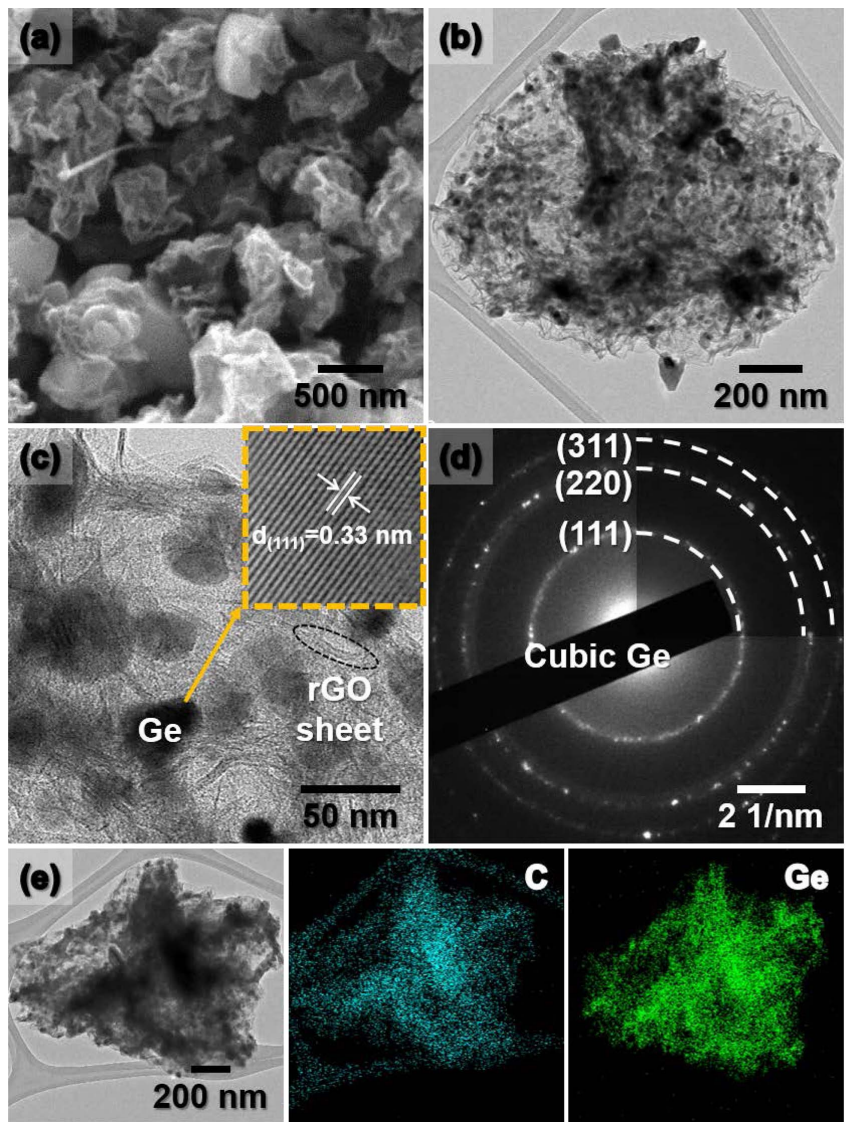

Fig. 2. Morphologies, SAED, and elemental mapping images of Ge-rGO powder: (a) SEM image, (b) TEM image, (c) HR-TEM image (the inset: lattice image), (d) SAED pattern, and (e) elemental mapping images.

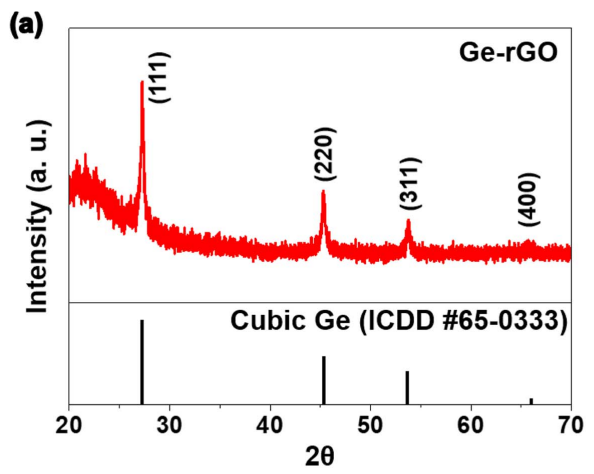

(b) \begin{tabular}{|c|c|c|c|c|}
\hline Sample & $\mathbf{C}(\mathbf{w t} \%)$ & $\mathbf{H}(\mathbf{w t} \%)$ & $\mathbf{N}(\mathbf{w t} \%)$ & $\mathbf{S}(\mathbf{w t} \%)$ \\
\hline Ge-rGO & 14.33 & 0.26 & 0.55 & 3.16 \\
\hline
\end{tabular}

Fig. 3. (a) XRD pattern and (b) CHNS analysis result of GerGO powder. 
(a)

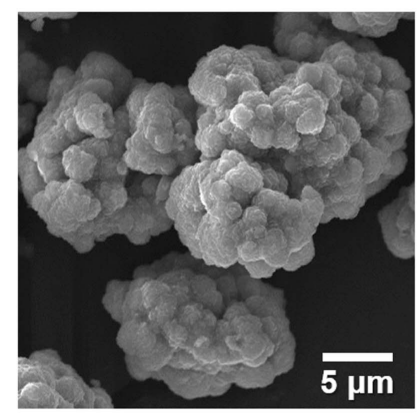

(b)

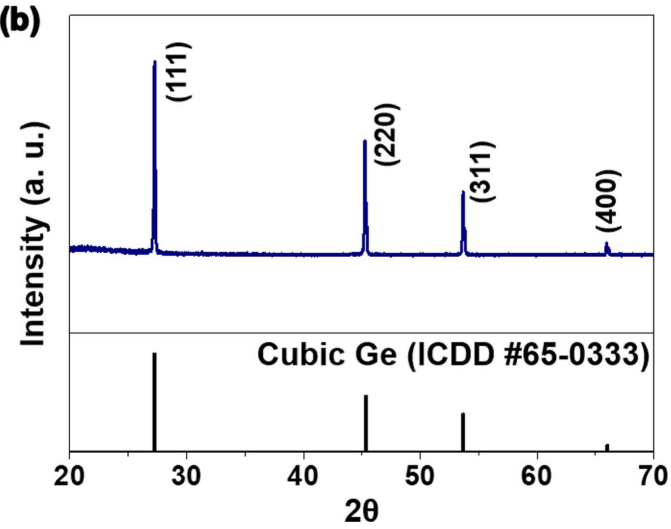

Fig. 4. (a) SEM image and (b) XRD pattern of Ge metal powders.

tion of $\mathrm{C}$ and $\mathrm{Ge}$ throughout the composite, indicating successful incorporation of the germanium nanocrystals and rGO sheets.

CHNS analysis was conducted to estimate the exact amount of the rGO content in Ge-rGO powder (Fig. 3(b)). According to the result, the carbon content of Ge-rGO was $14.3 \mathrm{wt} \%$. Slight amount of $\mathrm{N}$ and $\mathrm{S}$ components were also detected, which were likely to be derived from the ammonia solution and sulfuric acid that were used to dissolve $\mathrm{GeO}_{2}$ and prepare GO solution, respectively.

The Li-ion storage performance of the Ge-rGO composite powder was compared with that of $\mathrm{Ge}$ metal powder obtained by reducing $\mathrm{GeO}_{2}$ powder. The SEM image and XRD pattern of the Ge metal powder presented in Figs. 4(a) and $b$ indicate the formation of highly crystalline Ge metal after reduction. The $\mathrm{CV}$ curve of $\mathrm{Ge}-\mathrm{rGO}$ in the range of $0.001-3.0 \mathrm{~V}$ at a scan rate of $0.1 \mathrm{mV} \mathrm{s}^{-1}$ is shown in Fig. 5(a). In the first cathodic scan, reduction peaks appeared at 0.55 , $0.36,0.19$, and $0.06 \mathrm{~V}$. The peak at $0.55 \mathrm{~V}$ is attributed to the formation of a solid electrolyte interphase (SEI) layer. ${ }^{14,30,31)}$ This peak was not observed in the subsequent cycles, indicating the irreversibility of the reaction. The other peaks at lower potentials were attributed to the formation of $\mathrm{Li}_{\mathrm{x}} \mathrm{Ge}$ alloys such as $\mathrm{Li}_{7} \mathrm{Ge}_{2}, \mathrm{Li}_{9} \mathrm{Ge}_{4}$, and $\mathrm{Li}_{22} \mathrm{Ge}_{5}$ intermediates. ${ }^{28,30,35-37)}$ The large peak at $0.06 \mathrm{~V}$ also corresponded to the reversible Li-ion insertion into graphene. ${ }^{30,38)}$ From the second cycle onward, these reactions were observed at 0.41 and $0.09 \mathrm{~V}$. The oxidation peaks at 0.54 and $0.73 \mathrm{~V}$ in the anodic scan are ascribed to the delithiation reaction of the Li-Ge alloy. The small peak at $1.12 \mathrm{~V}$ was ascribed by the oxidation of $\mathrm{Ge}$ to $\mathrm{GeO}_{\mathrm{x}}{ }^{24,39)}$ This indicates that $\mathrm{Ge}$ nanoparticles on the rGO sheets were partially oxidized, since nanosized Ge crystal is more susceptible to the oxidation. From the second cycle onward, the curves overlapped, indicating good reversibility and stability of the reaction. Overall, the entire lithiation/delithiation reaction can be summarized as follows: ${ }^{15)}$

$$
\mathrm{Ge} \leftrightarrow \mathrm{Li}_{9} \mathrm{Ge}_{4} \leftrightarrow \mathrm{Li}_{7} \mathrm{Ge}_{2} \leftrightarrow \mathrm{Li}_{15} \mathrm{Ge}_{4}+\mathrm{Li}_{22} \mathrm{Ge}_{5}
$$

Figure 5(b) shows the CV curves of Ge metal. Compared with that of Ge-rGO, the first cathodic scan of Ge metal shows one large peak at $0.07 \mathrm{~V}$, which indicate the lithiation reaction. ${ }^{18)}$ Three peaks were observed at $0.46,0.35$, and $0.13 \mathrm{~V}$ in the subsequent cycles, indicating the multi-step lithiation reactions, as discussed above. The anodic peak at $0.63 \mathrm{~V}$ corresponds to the delithiation reaction. ${ }^{15,36)}$ From the second cycle onward, however, the intensities of the cathodic and anodic peaks diminished, indicating the instability of the electrode, mainly caused by pulverization during cycling. The initial discharge-charge profiles of the Ge-rGO and Ge metal powders are shown in Fig. 5(c). The discharge profile of Ge-rGO exhibited a distinctive plateau at roughly $0.5 \mathrm{~V}$, which matches to the reduction peak observed in the CV curve in Fig. 5(a). Similarly, the discharge profile of Ge metal powder exhibited a very distinctive plateau at $0.25 \mathrm{~V}$ that corresponds to the sharp reduction peak in Fig. 5(b). The charge profiles of the Ge-rGO and Ge metal powders showed a plateau around 0.3 and $0.5 \mathrm{~V}$, which also coincided with the oxidation peaks observed in the CV curves in Figs. 5(a) and (b). The initial discharge capacities of the Ge-rGO and Ge metal powders were 1443 and $1514 \mathrm{~mA} \mathrm{~h} \mathrm{~g}^{-1}$, respectively, and the corresponding charge capacities were 996 and $1341 \mathrm{~mA} \mathrm{~h} \mathrm{~g}^{-1}$. The low initial Coulombic efficiency of Ge-rGO resulted from the large irreversible capacity caused by decomposition of the electrolyte and formation of the SEI layer, which is generally affected by the surface area of the electrode. The cycling performance of the Ge-rGO and Ge metal powders at $1.0 \mathrm{~A} \mathrm{~g}^{-1}$ are presented in Fig. 5(d). The reversible discharge capacity of Ge-rGO was fairly stable over 200 cycles $\left(748 \mathrm{~mA} \mathrm{~h} \mathrm{~g}^{-1}\right)$, whereas that of Ge metal faded seriously after a few cycles, exhibiting the discharge capacity of merely $78 \mathrm{~mA} \mathrm{~h} \mathrm{~g}^{-1}$ at the $200^{\text {th }}$ cycle. The rate performance of the $\mathrm{Ge}-\mathrm{rGO}$ and Ge metal powders is summarized in Fig. 5(e). The discharge capacities of Ge-rGO at current densities of $0.5,1.0,2.0,3.0,4.0$, and 5.0 $\mathrm{A} \mathrm{g}^{-1}$ were $980,883,775,702,634$, and $375 \mathrm{~mA} \mathrm{~h} \mathrm{~g}^{-1}$, respectively. On the other hand, the discharge capacities of Ge metal at the corresponding current densities were 937, 747, $542,332,232$, and $160 \mathrm{~mA} \mathrm{~h} \mathrm{~g}^{-1}$. The superior electrochemical performance of Ge-rGO relative to that of Ge metal could be ascribed to the synergistic effect between the Ge nanocrystals and rGO. Incorporation of the Ge nanocrystals 

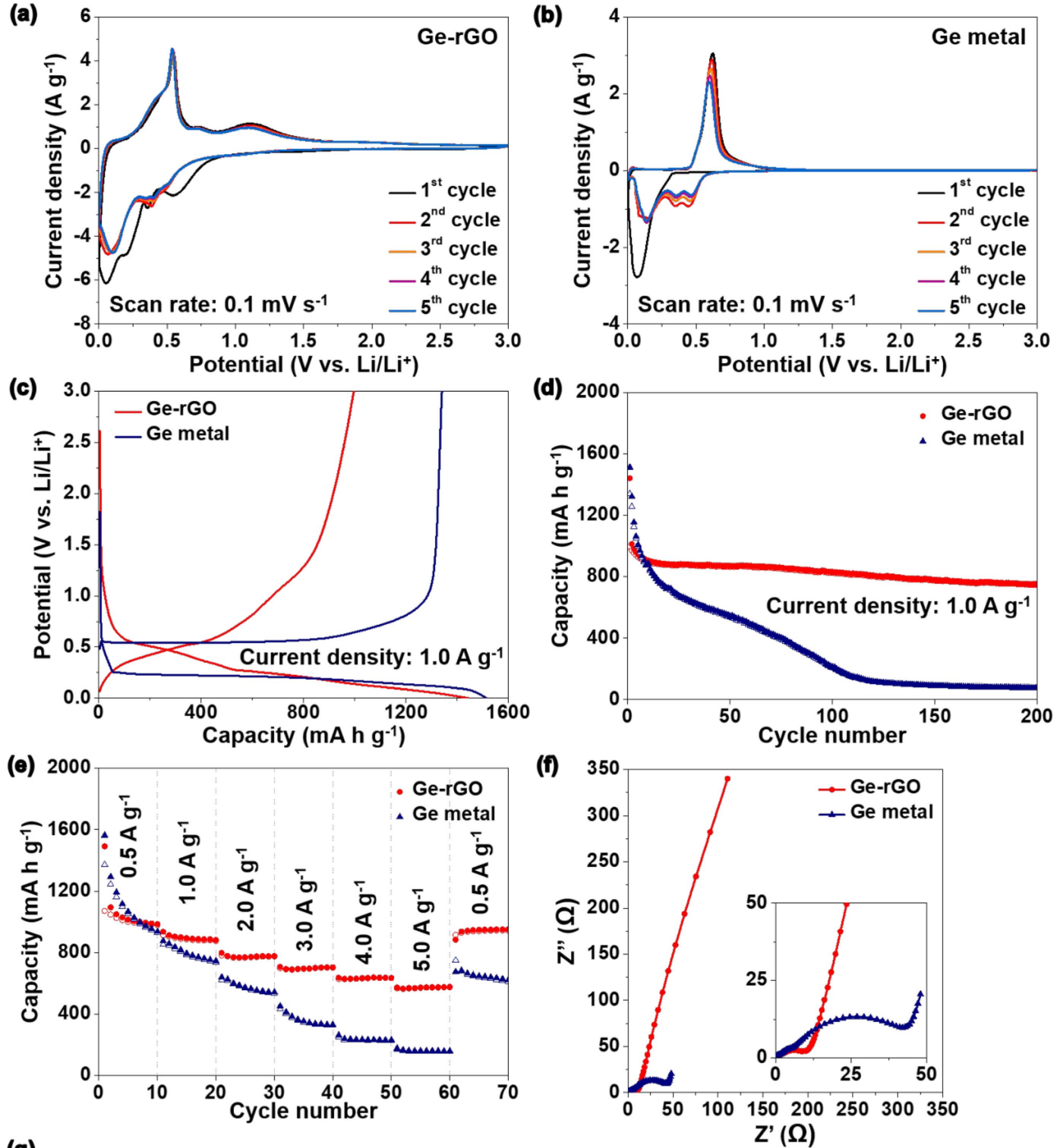

(g)

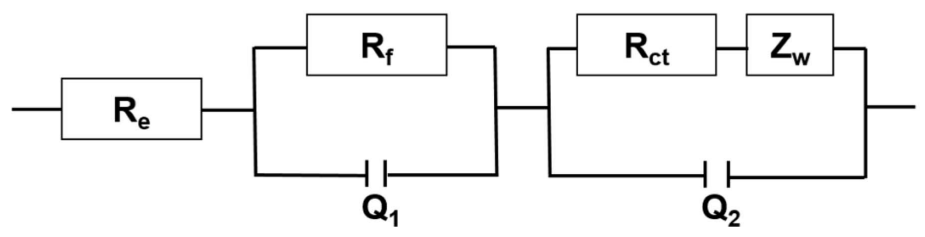

Fig. 5. Electrochemical properties of Ge-rGO and Ge metal powders: (a) CV curves of Ge-rGO, (b) CV curves of Ge metal, (c) first discharge-charge profiles, (d) cycling performances at a current density of $1.0 \mathrm{~A} \mathrm{~g}^{-1}$, (e) rate performances, (f) Nyquist plots obtained after $50^{\text {th }}$ cycle, and (g) Randle-type equivalent circuit model used for EIS.

with the rGO sheets effectively reduced the mechanical stress induced by the volume change of Ge during lithiation and delithiation, thus preventing pulverization of the electrode. ${ }^{16,23,27)}$ In addition, the open channel between the rGO sheets facilitated penetration of the electrolyte, which in turn provided ample sites for reaction of the $\mathrm{Li}$ ions with the Ge nanocrystals. Furthermore, the presence of rGO improved the electrical conductivity of the powder, contributing to the enhanced rate performance. ${ }^{14,30,31)}$ EIS analysis was employed to confirm the superior electrochemical performance of $\mathrm{Ge}-\mathrm{rGO}$ relative to that of Ge metal powder. The semicircle in the high-to-medium frequency region represents the charge-transfer resistance $\left(R_{\mathrm{ct}}\right)$ of the electrode. The Nyquist plots of the Ge-rGO and Ge metal powders from the halfcells, which were obtained after 50 cycles with fully charged state, are presented in Fig. 5(f). The plots were obtained by 
deconvolution with a Randle-type equivalent circuit model shown in Fig. 5(g). The electrochemical reaction types such as charge transfer reaction, lithium ion migration through SEI layers, and $\mathrm{Li}^{+}$ion diffusion kinetics in the active materials are described in the equivalent circuit model. The diameter of the semicircular region for Ge-rGO in Fig. 5(f) was smaller than that for Ge metal. The precise values of charge transfer resistance of Ge-rGO and Ge metal powders were acquired from the simulated equivalent circuit. Accordingly, the $R_{\text {ct }}$ values for the Ge-rGO and Ge metal powders were 10 and 48, respectively. The low $R_{\text {ct }}$ of Ge-rGO is attributed to its structural stability and high electrical conductivity, which is in accord with the superior cycling stability and rate performance. ${ }^{30,40)}$

\section{Conclusions}

In this study, the enhanced electrochemical properties of a $\mathrm{Ge}-\mathrm{rGO}$ powder as anode material for LIBs were confirmed. Successful incorporation of Ge and rGO nanosheets was achieved by simple spray pyrolysis and subsequent $\mathrm{H}_{2}$ reduction. The synergistic effect between the robust, highly conductive rGO nanosheets and Ge improved the cycling stability and rate performance of the resulting composite. Thus, Ge-rGO powder could exhibit a stable reversible discharge capacity over 200 cycles and good rate performance at a high current density of $5 \mathrm{~A} \mathrm{~g}^{-1}$.

\section{Acknowledgements}

This work was supported by the National Research Foundation of Korea (NRF) grant funded by the Korea government (MSIP) (No. 2017R1A2B2008592).

\section{REFERENCES}

1. K. Kang, Y. S. Meng, J. Bréger, C. P. Grey, and G. Ceder, "Electrodes with High Power and High Capacity for Rechargeable Lithium Batteries," Science, 311 [5763] 97780 (2006).

2. B. Kang and G. Ceder, "Battery Materials for Ultrafast Charging and Discharging," Nature, 458 190-93 (2009).

3. L. Ji, Z. Lin, M. Alcoutlabi, and X. Zhang, "Recent Developments in Nanostructured Anode Materials for Rechargeable Lithium-Ion Batteries," Energy Environ. Sci., 4 [8] 2682-99 (2011).

4. L. Lu, X. Han, J. Li, J. Hua, and M. Ouyang, "A Review on the Key Issues for Lithium-Ion Battery Management in Electric Vehicles," J. Power Sources, 226 272-88 (2013).

5. S. Goriparti, E. Miele, F. De Angelis, E. Di Fabrizio, R. Proietti Zaccaria, and C. Capiglia, "Review on Recent Progress of Nanostructured Anode Materials for Li-Ion Batteries," J. Power Sources, 257 421-43 (2014).

6. X. Li, J. Liang, Z. Hou, W. Zhang, Y. Wang, Y. Zhu, and Y. Qian, "The Design of a High-Energy Li-Ion Battery Using Germanium-Based Anode and $\mathrm{LiCoO}_{2}$ Cathode," J. Power Sources, 293 868-75 (2015).
7. T. Kennedy, E. Mullane, H. Geaney, M. Osiak, C. O'Dwyer, and K. M. Ryan, "High-Performance Germanium Nanowire-Based Lithium-Ion Battery Anodes Extending over 1000 Cycles through in situ Formation of a Continuous Porous Network," Nano Lett., 14 [2] 716-23 (2014).

8. D.-J. Xue, S. Xin, Y. Yan, K.-C. Jiang, Y.-X. Yin, Y.-G. Guo, and L.-J. Wan, "Improving the Electrode Performance of Ge through Ge@C Core-Shell Nanoparticles and Graphene Networks," J. Am. Chem. Soc., 134 [5] 2512-15 (2012).

9. M. H. Park, Y. Cho, K. Kim, J. Kim, M. Liu, and J. Cho, "Germanium Nanotubes Prepared by Using the Kirkendall Effect as Anodes for High-Rate Lithium Batteries," Angew. Chem. Int. Ed., 50 [41] 9647-50 (2011).

10. D. T. Ngo, R. S. Kalubarme, H. T. T. Le, J. G. Fisher, C.N. Park, I.-D. Kim, and C.-J. Park, "Carbon-Interconnected Ge Nanocrystals as an Anode with Ultra-Long-Term Cyclability for Lithium Ion Batteries," Adv. Funct. Mater., 24 [33] 5291-98 (2014).

11. J. D. Ocon, J. K. Lee, and J. Lee, "High Energy Density Germanium Anodes for Next Generation Lithium Ion Batteries," Appl. Chem. Eng., 25 [1] 1-13 (2014).

12. K. H. Seng, M. H. Park, Z. P. Guo, H. K. Liu, and J. Cho, "Self-Assembled Germanium/Carbon Nanostructures as High-Power Anode Material for the Lithium-Ion Battery," Angew. Chem. Int. Ed., 124 [23] 5755-59 (2012).

13. X. Su, Q. Wu, J. Li, X. Xiao, A. Lott, W. Lu, B. W. Sheldon, and J. Wu, "Silicon-Based Nanomaterials for Lithium-Ion Batteries: A Review," Adv. Energy Mater., 4 [1] 1300882 (2014).

14. S. Fang, L. Shen, H. Zheng, and X. Zhang, "Ge-GrapheneCarbon Nanotube Composite Anode for High Performance Lithium-Ion Batteries," J. Mater. Chem. A, 3 [4] 1498-503 (2015).

15. X. Gao, W. Luo, C. Zhong, D. Wexler, S. L. Chou, H. K. Liu, Z. Shi, G. Chen, K. Ozawa, and J. Z. Wang, "Novel Germanium/Polypyrrole Composite for High Power Lithium-Ion Batteries," Sci. Rep., 46095 (2014).

16. S. Wu, C. Han, J. Iocozzia, M. Lu, R. Ge, R. Xu, and Z. Lin, "Germanium-Based Nanomaterials for Rechargeable Batteries," Angew. Chem. Int. Ed., 55 [28] 7898-922 (2016).

17. W. He, H. Tian, X. Wang, F. Xin, and W. Han, "ThreeDimensional Interconnected Network $\mathrm{GeO}_{\mathrm{x}} / \mathrm{Multi}$-Walled CNT Composite Spheres as High-Performance Anodes for Lithium Ion Batteries," J. Mater. Chem. A, 3 [38] 19393401 (2015).

18. L. Wang, K. Bao, Z. Lou, G. Liang, and Q. Zhou, "Chemical Synthesis of Germanium Nanoparticles with Uniform Size as Anode Materials for Lithium Ion Batteries," Dalt. Trans., 45 [7] 2814-17 (2016).

19. C. K. Chan, X. F. Zhang, and Y. Cui, "High Capacity LiIon Battery Anodes Using Ge Nanowires," Nano Lett., 8 [1] 307-9 (2008).

20. G.-H. Lee, H.-W. Shim, and D.-W. Kim, "Superior LongLife and High-Rate Ge Nanoarrays Anchored on $\mathrm{Cu} / \mathrm{C}$ Nanowire Frameworks for Li-Ion Battery Electrodes," Nano Energy, 13 218-25 (2015).

21. H. S. Im, Y. R. Lim, Y. J. Cho, J. Park, E. H. Cha, and H. S. Kang, "Germanium and Tin Selenide Nanocrystals for High-Capacity Lithium Ion Batteries: Comparative Phase 
Conversion of Germanium and Tin," J. Phys. Chem. C, 118 [38] 21884-88 (2014).

22. S. Wu, R. Xu, M. Lu, R. Ge, J. Iocozzia, C. Han, B. Jiang, and Z. Lin, "Graphene-Containing Nanomaterials for Lithium-Ion Batteries," Adv. Energy Mater., 5 [21] 1500400 (2015).

23. S. H. Choi, K. Y. Jung, and Y. C. Kang, "Amorphous $\mathrm{GeO}_{x^{-}}$ Coated Reduced Graphene Oxide Balls with Sandwich Structure for Long-Life Lithium-Ion Batteries," ACS Appl. Mater. Interfaces, 7 [25] 13952-59 (2015).

24. J. K. Kim, G. D. Park, J. H. Kim, J. H. Kim, and Y. C. Kang, "Electrochemical Properties of Amorphous $\mathrm{GeO}_{\mathrm{x}}-\mathrm{C}$ Composite Microspheres Prepared by a One-Pot Spray Pyrolysis Process," Ceram. Int., 43 [7] 5534-40 (2017).

25. Y. J. Cho, H. S. Im, H. S. Kim, Y. Myung, S. H. Back, Y. R. Lim, C. S. Jung, D. M. Jang, J. Park, E. H. Cha, W. I. Cho, F. Shojaei, and H. S. Kang, "Tetragonal Phase Germanium Nanocrystals in Lithium Ion Batteries," ACS Nano, 7 [10] 9075-84 (2013).

26. J. Gu, S. M. Collins, A. I. Carim, X. Hao, B. M. Bartlett, and S. Maldonado, "Template-Free Preparation of Crystalline Ge Nanowire Film Electrodes via an Electrochemical Liquid-Liquid-Solid Process in Water at Ambient Pressure and Temperature for Energy Storage," Nano Lett., 12 [9] 4617-23 (2012).

27. C. Wang, J. Ju, Y. Yang, Y. Tang, J. Lin, Z. Shi, R. P. S. Han, and F. Huang, "In situ Grown Graphene-Encapsulated Germanium Nanowires for Superior Lithium-Ion Storage Properties," J. Mater. Chem. A, 1 [31] 8897-902 (2013).

28. J.-G. Ren, Q.-H. Wu, H. Tang, G. Hong, W. Zhang, and S.T. Lee, "Germanium-Graphene Composite Anode for HighEnergy Lithium Batteries with Long Cycle Life," J. Mater. Chem. A, 1 [5] 1821-26 (2013).

29. J. Cheng and J. Du, "Facile Synthesis of GermaniumGraphene Nanocomposites and Their Application as Anode Materials for Lithium Ion Batteries," CrystEngComm, 14 [2] 397-400 (2012).

30. C. Gao, N. D. Kim, R. Villegas Salvatierra, S.-K. Lee, L. Li, Y. Li, J. Sha, G. A. L. Silva, H. Fei, E. Xie, and J. M. Tour, "Germanium on Seamless Graphene Carbon Nanotube Hybrids for Lithium Ion Anodes," Carbon, 123 43339 (2017)
31. Y. Xu, X. Zhu, X. Zhou, X. Liu, Y. Liu, Z. Dai, and J. Bao, "Ge Nanoparticles Encapsulated in Nitrogen-Doped Reduced Graphene Oxide as an Advanced Anode Material for Lithium-Ion Batteries," J. Phys. Chem. C, 118 [49] 28502-08 (2014).

32. D. Li, C. Feng, H. Liu, and Z. Guo, "Hollow Carbon Spheres with Encapsulated Germanium as an Anode Material for Lithium Ion Batteries," J. Mater. Chem. A, 3 [3] 978-81 (2015).

33. D. Li, K. H. Seng, D. Shi, Z. Chen, H. K. Liu, and Z. Guo, "A Unique Sandwich-Structured C/Ge/Graphene Nanocomposite as an Anode Material for High Power Lithium Ion Batteries," J. Mater. Chem. A, 1 [45] 14115-21 (2013).

34. J. K. Kim, J. H. Kim, and Y. C. Kang, "Electrochemical Properties of Multicomponent Oxide and Selenide Microspheres Containing Co and Mo Components with Several Tens of Vacant Nanorooms Synthesized by Spray Pyrolysis," Chem. Eng. J., 333 665-77 (2018).

35. Yoon, C.-M. Park, and H.-J. Sohn, "Electrochemical Characterizations of Germanium and Carbon-Coated Germanium Composite Anode for Lithium-Ion Batteries," Electrochem. Solid-State Lett., 11 [4] A42-5 (2008).

36. A. M. Chockla, M. G. Panthani, V. C. Holmberg, C. M. Hessel, D. K. Reid, T. D. Bogart, J. T. Harris, C. B. Mullins, and B. A. Korgel, "Electrochemical Lithiation of Graphene-Supported Silicon and Germanium for Rechargeable Batteries," J. Phys. Chem. C, 116 [22] 11917-23 (2012).

37. C. Zhang, Z. Lin, Z. Yang, D. Xiao, P. Hu, H. Xu, Y. Duan, S. Pang, L. Gu, and G. Cui, "Hierarchically Designed Germanium Microcubes with High Initial Coulombic Efficiency toward Highly Reversible Lithium Storage," Chem. Mater., 27 [6] 2189-94 (2015).

38. E. Yoo, J. Kim, E. Hosono, H. Zhou, T. Kudo, and I. Honma, "Large Reversible Li Storage of Graphene Nanosheet Families for Use in Rechargeable Lithium Ion Batteries," Nano Lett., 8 [8] 2277-82 (2008).

39. S. Jin, N. Li, H. Cui, and C. Wang, "Growth of the Vertically Aligned Graphene@Amorphous $\mathrm{GeO}_{\mathrm{x}}$ Sandwich Nanoflakes and Excellent Li Storage Properties," Nano Energy, 2 [6] 1128-36 (2013).

40. K. Lee, S. Y. Shin, and Y. S. Yoon, " $\mathrm{Fe}_{3} \mathrm{O}_{4}$ Nanoparticles on MWCNTs Backbone for Lithium Ion Batteries," $J$. Korean Ceram. Soc., 53 [3] 376-80 (2016). 